\title{
AVALIAÇÃO DA CONDUTIVIDADE HIDRÁULICA EM ÁREAS DE RECARGA DO AQUÍFERI GUARANI - MICROBACIA HIDROGRÁFICA URBANA DO RIO BACACHERI (PR).
}

\author{
P.F. MILCZEWSKI ${ }^{1}$, L. ZAIA ${ }^{2}$, T. HU ${ }^{2}$, A.L. MATHIAS ${ }^{1}$, R. WEINSCHUTZ ${ }^{1,2}$, R.M.M. \\ $\mathrm{JORGE}^{1,2^{*}}$
}

${ }^{1}$ Programa de Pós-Graduação em Meio Ambiente Urbano e Industrial, Departamento de Engenharia Química - Universidade Federal do Paraná (UFPR).

${ }^{2}$ PRH-24- Programa Interdisciplinar de Petróleo e Gás Natural da UFPR, Departamento de Engenharia Química, Universidade Federal do Paraná (UFPR).

*E-mail para contato: pallomafm@ @ sanepar.com.br, rjorge@ufpr.br

\begin{abstract}
RESUMO - No mundo, estima-se que $87 \%$ dos combustíveis são derivados de petróleo. Isto faz dos postos revendedores, uma das principais fontes de contaminação do solo e águas subterrâneas. No ambiente, o combustível sofre a influência de diversos mecanismos que aumentam a velocidade de dispersão e/ou retardam sua locomoção. Os processos de retenção aprisionam o contaminante, diminuindo extremamente sua mobilidade, todavia este passa a funcionar como uma fonte gradativa de contaminação, liberando poluentes de forma lenta e contínua, podendo atingir o lençol freático. Neste trabalho, realizaram-se ensaios com o intuito de caracterizar o comportamento de absorção por capilaridade da gasolina oxigenada em amostras de solo coletadas ao longo da Bacia Hidrográfica do Rio Bacacheri - Curitiba/PR. Este parâmetro permite avaliar a influência do tipo de solo e da umidade na Capacidade de Retenção Volumétrica Máxima de Combustível. Esta informação possibilita, entre outras coisas, estimar o volume de solo necessário para reter um vazamento antes que substâncias tóxicas, como o benzeno, atinjam o aquífero. A Bacia do Rio Bacacheri compõe a Bacia do Alto Iguaçu, que pode ser considerada uma área de recarga do Sistema Aquífero Guarani.
\end{abstract}

\section{INTRODUÇÃO}

O Brasil conta atualmente com uma frota de mais de 64,8 milhões de veículos automotores. Para abastecê-los, estão espalhados por todo o território nacional, 39.163 postos revendedores de combustíveis líquidos. Estes se concentram principalmente nos grandes centros urbanos, como Curitiba, que possui aproximadamente 634 postos cadastrados, sendo que destes, 40 estão instalados na Bacia do Rio Bacacheri. (ANP, 2014). 
A Bacia Hidrográfica do Rio Bacacheri está localizada na porção Nordeste da Cidade de Curitiba/PR, compreendida entre as coordenadas geográficas de latitude $25^{\circ} 21^{\prime} 04^{\prime \prime} \mathrm{S}$ a $25^{\circ} 26^{\prime} 58^{\prime}$ 'S e Longitude de $49^{\circ} 16^{\prime} 15^{\prime \prime} \mathrm{W}$ a $49^{\circ} 11^{\prime} 59^{\prime} \mathrm{W}$. Formada principalmente pelos rios Bacacheri e Bacacheri Mirim, sua área total de drenagem é de $30,81 \mathrm{~km}^{2}$. A bacia corta ao todo dez bairros, desde suas nascentes no bairro Cachoeira até a sua foz, onde desemboca no rio Atuba no bairro Capão da Imbuia. (Ribeiro, 2002).

A exemplo do que ocorre em todo o Brasil, muitos dos postos de combustíveis instalados na bacia em questão, possuem mais de 30 anos, vários destes com tanques e tubulações enferrujados. Alguns possuem históricos de vazamentos e outros já foram interditados por terem causado acidentes. Este tipo de atividade varejista representa grande preocupação ao meio ambiente, sendo no país, uma das principais causas de acidentes ambientais, conforme dados da Companhia Ambiental do estado de São Paulo (CETESB), da Fundação Estadual de Engenharia do Meio Ambiente (FEEMA) no Rio de Janeiro e do Instituto Ambiental do Paraná (IAP). (Milczewski, 2010).

A Bacia do rio Bacacheri compõe a Bacia Hidrográfica do Alto Iguaçu, que atravessa todo o Paraná e passa por áreas de recarga direta e indireta do principal aquífero do estado, o Aquífero Guarani. Isto significa que mesmo que forma indireta, um vazamento nesta região poderá levar danos à qualidade de água do aquífero.

O Sistema do Aquífero Guarani (SAG) é considerado pela comunidade científica como um dos maiores reservatórios de água potável, subterrânea, do mundo. Segundo o Ministério do Meio Ambiente, este corpo hídrico subterrâneo é classificado como transfronteiriço, pois além de estar presente em oito estados brasileiros - Paraná, Santa Catarina, Rio Grande do Sul, São Paulo, Minas Gerais, Goiás, Mato Grosso e Mato Grosso do Sul - ainda abrange parte dos territórios da Argentina, Paraguai e Uruguai. (MMA, 2014).

Trata-se de um aquífero confinado de aproximadamente $1.194 .800 \mathrm{~km}^{2}$, recoberto por derrames de lavas basálticas dos Períodos Triássico, Jurássico e Cretáceo Inferior, de mais de 100 milhões de anos, com porosidade e permeabilidade muito variáveis. A profundidade varia de 0 a 1.800 metros. Constitui-se em uma importante reserva estratégica para o abastecimento da população, visto que em termos de vazão, pode-se obter mais de 200 mil litros por hora, em arenitos da Formação Botucatu e ainda conta com uma recarga natural na ordem de 160 km³/ano. Nas margens do aquífero, a erosão expõe pedaços do arenito, em áreas denominadas de afloramentos. Por estas áreas ocorre a recarga direta e indireta do Guarani, através de dois mecanismos: infiltração direta das águas de chuva; e infiltração vertical ao longo de descontinuidades nas áreas de confinamento, num processo mais lento. É mister destacar que nestas áreas de recarga o aquífero Guarani apresenta-se mais vulnerável a contaminações. (Águas Paraná, 2014).

Um vazamento de combustível em área de bacia hidrográfica faz com que os danos gerados ao meio ambiente sejam potencializados, visto que ao ocorrer o vazamento, a velocidade de difusão do contaminante é maior ao atingir o corpo hídrico, seja ele superficial ou subterrâneo. Este tipo de acidente pode contaminar fontes de abastecimento de água com hidrocarbonetos monoaromáticos, extremamente tóxicos, como o benzeno, tolueno, etilbenzeno e xilenos (BTEX) que além de cancerígenas são depressores do sistema nervoso central. (Coreseuil \& Marins, 1997). 
Ao atingir o solo, o combustível poderá ser transportado por inúmeros mecanismos, como: a volatilização, solubilização, advecção, adsorção, decaimento, entre outros. Alguns destes mecanismos aumentam a velocidade de dispersão e outros retardam a sua locomoção. Os processos de retenção - adsorção, absorção e sorção hidrofóbica - aprisionam o combustível no solo, diminuindo extremamente a sua mobilidade, todavia estes passam a funcionar como uma fonte gradativa de contaminação, liberando os poluentes de forma lenta e contínua, possibilitando que o mesmo atinja o lençol freático.

$\mathrm{Na}$ presente pesquisa realizaram-se ensaios em amostras indeformadas de solo retiradas ao longo da Bacia Hidrográfica do rio Bacacheri, com o objetivo de se obter a Capacidade de Retenção Máxima para os diferentes tipos de solo da região, e também de se caracterizar o comportamento de capilaridade da Gasolina Tipo C (acrescida de Etanol Anidro) no solo.

\section{MATERIAIS E MÉTODOS.}

Com o mapa de solos da bacia do rio Bacacheri, estabeleceu-se 04 (quatro) pontos para amostragem, sendo dois próximos as nascentes, cada um em um tipo de solo diferente, um terceiro ponto no meio da bacia e um ultimo ponto próximo a foz.

Para as amostragens e realização dos ensaios foram confeccionados cilindros em aço inox, de diâmetro externo de $\varnothing 76,20 \mathrm{~mm}$, diâmetro interno de $\varnothing 70,20 \mathrm{~mm}$ e altura de $80 \mathrm{~mm}$. As amostras indeformadas foram retiradas a uma profundidade média de $30 \mathrm{~cm}$, inserindo os cilindros no solo, em posição vertical até que estes estivessem completamente soterrados, posteriormente foram cuidadosamente retirados com o auxilio de cortadeira, para que o solo se mantivesse intacto no interior do cilindro. Após este procedimento, as amostras foram embaladas com plástico filme, para assegurar que mantivessem a umidade natural, e foram imediatamente levadas ao laboratório para análise.

Algumas amostras foram ensaiadas in natura, ou seja, preservando-se a umidade natural do momento em que foram coletadas. E outras passaram pelo processo de secagem em estufa a $110^{\circ} \mathrm{C}$, pelo período de 24 horas. Nestes casos, o cilindro contendo solo era pesado antes e depois da secagem, para obter-se a porcentagem de umidade das amostras. Após saírem da estufa, as amostras eram resfriadas naturalmente em dissecador, antes de realizar a segunda pesagem.

A metodologia dos ensaios para verificar a capacidade máxima de retenção de gasolina dos solos, bem como seu comportamento de absorção por capilaridade foi adaptada dos autores Ribeiro (1999) e Duarte (2003).

Após a pesagem inicial, as amostras de solo eram montadas para o ensaio. A montagem consistia em colocar um disco de papel filtro em uma das extremidades do cilindro e fixá-lo com o auxilio de uma peneira inoxidável de malha fina que serviu como tampa do conjunto, para evitar a perda de solo durante os ensaios, sem prejudicar a passagem dos líquidos. $\mathrm{O}$ excesso de papel é retirado e o conjunto, novamente pesado.

Em uma capela, no fundo de um recipiente de vidro, com diâmetro aproximado de $12 \mathrm{~cm}$ 
e altura de $10 \mathrm{~cm}$, era colocada uma pedra porosa, e acrescido gasolina comum do tipo C contendo $25 \%$ de Etanol Anidro, igual à comercializada em todo o país. A gasolina era nivelada para ficar ligeiramente acima do nível da pedra porosa, e com o auxilio de uma pipeta, este nível foi mantido constante durante todo o ensaio.

No momento em que o conjunto de inox, contendo a amostra, era posto sobre a pedra porosa, o cronômetro era disparado, e em períodos que variavam de 1 a 5 minutos, o cronômetro era paralisado, a amostra era erguida e após escorrer o excesso de líquido, o conjunto era pesado novamente. Para as pesagens, utilizou-se uma balança analítica de precisão de 0,01g. A Figura 2 detalha a montagem do ensaio.
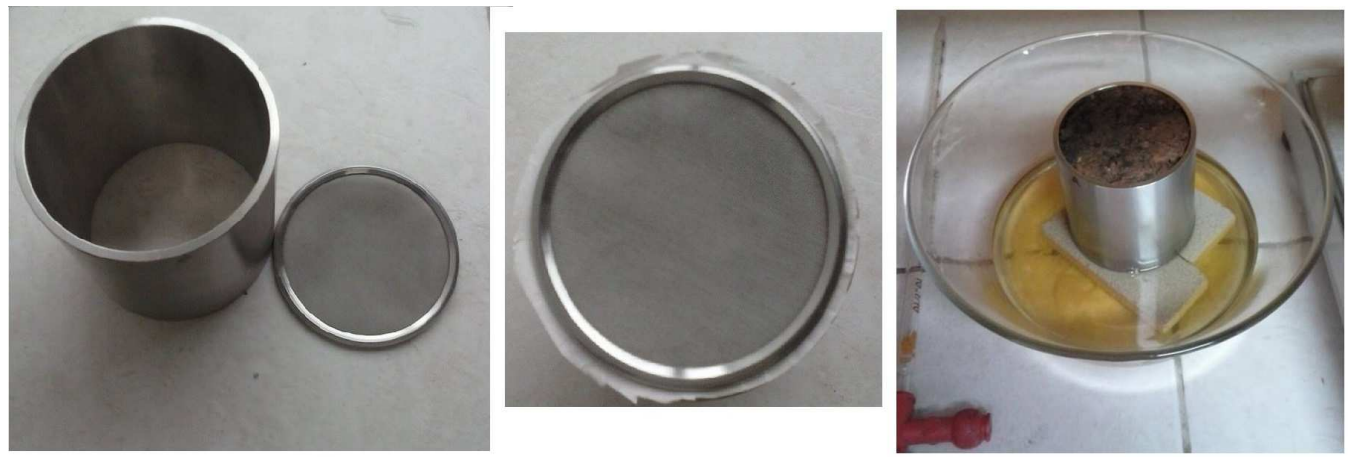

Figura 1 - À direita, o cilindro de inox junto com a peneira utilizada como tampa que era encaixada em seu interior. Ao centro o papel filtro, sobre o cilindro sendo fixado com o auxílio da tampa. À esquerda o conjunto montado, durante um ensaio utilizando Gasolina Tipo C.

Cada ensaio durou aproximadamente 90 minutos e foram coletadas e analisadas ao todo 24 amostras de solo, sendo 06 amostras de cada ponto. Todos os ensaios foram realizados em duplicata, para amostras de solo in natura e secas, utilizando a gasolina, e também para amostras secas utilizando água para fins comparativos. Os resultados destes ensaios são apresentados e discutidos no capítulo a seguir.

\section{RESULTADOS E DISCUSSÕES}

Segundo Ribeiro (1999), as equações que normalmente são utilizadas para caracterizar a infiltração ou drenagem do solo, também podem ser utilizadas para caracterizar a absorção por capilaridade, através da medida de outros parâmetros inerentes a esses processos.

Ainda segundo o mesmo autor, quando o processo de preenchimento dos vazios termina, ou seja, quando a infiltração ou a absorção se faz praticamente constante, a Lei de Darcy passa a ser aplicável. A diminuição da absorção de um líquido por um solo, ocorre devido a uma série de causas, dentre as quais a diminuição do tamanho dos poros do solo, desagregação dos microagregados estruturais, melhor arranjo das partículas devido à dispersão 
da fração de argila, entre outras. A gasolina é capaz de, por adsorção específica, afastar o solo, dispersando as partículas coloidais, sejam argilosas ou não.

Dentre os tipos de solo presentes na bacia estudada, foram coletadas amostras de três tipos diferentes, considerados os mais representativos. Os quatro pontos foram georreferenciados, e podem ser visualizados na Figura 2:

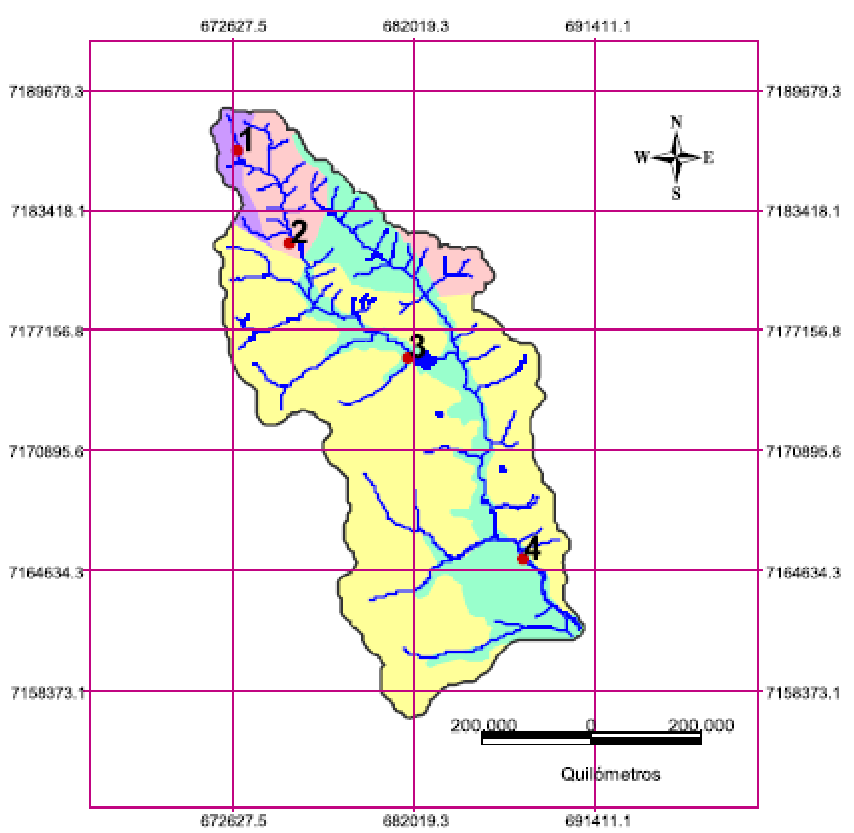

\begin{tabular}{|l|}
\hline LEGENDA: \\
Malha Urbana \\
Latossolos Bruno Distróficos \\
Gleissolos Melânicos Indiscriminados \\
Cambissolos - Tb Distróficos \\
Organossolos Mésicos \\
$\square$ Limite da Bacia \\
Hidrografia \\
Pontos de Coleta de Amostras
\end{tabular}

Sistems de Projaço UTM Datum Vertical Inbituba - SC Datuen Horizontal SAD69

Fonte: MINEROPAR

Elaborado: Pallocoa da Felix Milczewski

Figura 2 - Mapa do Tipo de Solos da Bacia Hidrográfica do Rio Bacacheri, com a demarcação dos pontos onde foram realizadas as amostragens de solo utilizadas nos ensaios.

Como era de se esperar, os resultados apresentados pelos ensaios realizados nos pontos 3 e 4, são bem semelhantes, visto tratar-se do mesmo tipo de solo - Gleissolos Melânicos Indiscriminados. Já o solo característico do ponto 1 - Latossolos Bruno Distróficos apresentou os menores índices de absorção e retenção, seja de gasolina ou de água. Isto pode ser explicado devido à densidade deste tipo de solo. Os resultados da Capacidade de Retenção Volumétrica Máxima, para cada tipo de solo, são mostrados na Tabela 1. 
Tabela 1 - Resultados do Ensaio de Capacidade de Retenção de Gasolina e Água em Relação aos Diferentes Tipos de Solo

\begin{tabular}{|c|c|c|c|c|}
\hline TIPO DE SOLO & TIPO DE ENSAIO & $\mathrm{V}_{\max -\mathrm{Liq}}\left(\mathrm{cm}^{3}\right)$ & $\mathrm{V}_{\text {solo }}\left(\mathrm{cm}^{3}\right)$ & $\begin{array}{c}\text { RVL ( } \mathrm{cm}^{3} \text { de líquid o/ } \\
\mathrm{cm}^{3} \text { de solo) }\end{array}$ \\
\hline \multirow{3}{*}{$\begin{array}{l}\text { PONTO } 1 \text { - Latossolos } \\
\text { Bruno Distróficos }\end{array}$} & SOLO IN NATURA X G ASOLINA & 7,5 & 325,72 & 0,023 \\
\hline & SOLO SECO X GASOLINA & 94,6 & 325,72 & 0,290 \\
\hline & SOLO SECO X ÁGUA & 101,5 & 325,72 & 0,312 \\
\hline \multirow{3}{*}{$\begin{array}{c}\text { PONTO } 2 \text { - Cambissol os } \mathrm{Tb} \\
\text { Distróficos }\end{array}$} & SOLO IN NATURA X GASOLINA & 8,2 & 244,29 & 0,034 \\
\hline & SOLO SECO X GASOLINA & 104,9 & 309,434 & 0,339 \\
\hline & SOLO SECO X ÁGUA & 121,71 & 285,005 & 0,427 \\
\hline \multirow{3}{*}{$\begin{array}{l}\text { PONTO } 3 \text { - Gleissolos } \\
\text { Melânicos Indiscrim. }\end{array}$} & SOLO IN NATURA X G ASOLINA & 44,0 & 325,72 & 0,135 \\
\hline & SOLO SECO X G ASOLINA & 75,8 & 325,72 & 0,233 \\
\hline & SOLO SECO X ÁGUA & 136,99 & 325,72 & 0,421 \\
\hline \multirow{3}{*}{$\begin{array}{l}\text { PONTO } 4 \text { - Gleissolos } \\
\text { Melânicos Indiscrim. }\end{array}$} & SOLO IN NATURA X G ASOLINA & 41,8 & 325,72 & 0,128 \\
\hline & SOLO SECO X GASOLINA & 78,3 & 325,72 & 0,240 \\
\hline & SOLO SECO X AGUA & 137,91 & 325,72 & 0,423 \\
\hline $\begin{array}{l}\text { Vmax - Liq }\left(\mathrm{cm}^{3}\right)-\text { Volume } \\
\text { Vsolo }\left(\mathrm{cm}^{3}\right)-\text { Volume do Co } \\
\operatorname{RVC}\left(\mathrm{cm}^{3} \text { de combustí el } / \mathrm{c}\right.\end{array}$ & $\begin{array}{l}\text { iximo de Líquid o (G asolina ou Água) } \\
\text { o de Prova } \\
\text { de solo) - Retenção Volumétrica Máx }\end{array}$ & $\begin{array}{l}\text { tid o pelo Solo em } \\
\text { a de Líquido }\end{array}$ & & \\
\hline
\end{tabular}

A importância de se obter o valor de RVC (Retenção Volumétrica de Combustível) é que num caso de vazamento, ele permite quantificar, mesmo que aproximadamente, quanto de combustível um determinado tipo de solo é capaz de reter em seus poros, por meio de forças capilares entre outros fatores, viabilizando uma previsão de qual o volume de solo necessário para reter o combustível vazado antes que este alcance um aquífero.

Considere-se o seguinte exemplo. Na região do ponto 3 (onde existe uma elevada densidade de postos por área), ocorre um pequeno vazamento de 50 litros de gasolina. Se naquela região o solo úmido tem uma RVL de $0,135 \mathrm{~cm}^{3}$ de liq $/ \mathrm{cm}^{3}$ de solo, será preciso um volume de solo de $370.370,37 \mathrm{~cm}^{3}$ (ou $0,37 \mathrm{~m}^{3}$ ) para manter este vazamento retido nos espaços intergranulares disponíveis, no limite da saturação.

O percentual de umidade das amostras analisadas in natura foi de aproximadamente $15 \%$. É válido informar que as amostras foram coletadas em período chuvoso. Tal umidade afetou significativamente a capacidade de absorção e retenção de todos os tipos de solo, o que fica bem evidenciado na Figura 3.

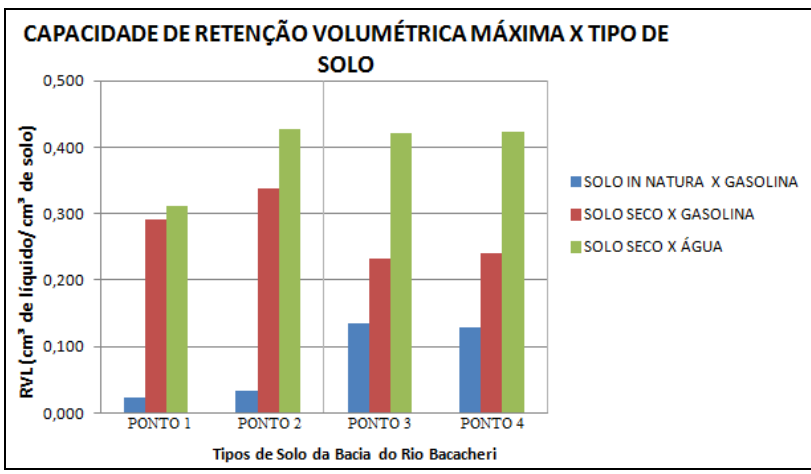

Figura 3 - Capacidade de Retenção Volumétrica Máxima em Relação aos Tipos de Solo Presentes na Bacia do Rio Bacacheri. 
A influência da umidade, sobre a Capacidade de Retenção, se justifica no fato de que quanto maior é o teor de água no solo, maior deve ser a dificuldade de o fluido migrar através do meio poroso, principalmente no caso da gasolina, isto porque o combustível precisa competir com a água para preencher os espaços intersticiais do solo, visto não serem completamente miscíveis. Por este mesmo motivo, é que a absorção e retenção máxima de água foram maiores do que a capacidade de retenção de gasolina, em relação às amostras de solo secas.

A absorção, em qualquer um dos casos analisados, não varia linearmente com o tempo, mas segundo curvas sigmoides. Uma análise mais apurada mostrou que o processo de absorção obedece a uma lei de potenciação. O comportamento dos diferentes tipos de solo durante cada ensaio, não apresentou grandes diferenças, sendo que a taxa de absorção inicial era maior nos primeiros minutos, e depois passava a sofrer uma desaceleração, até atingir o máximo, quando se mantinha constante. A principal diferença entre eles está na quantidade final absorvida. Este comportamento pode ser visualizado na Figura 4.

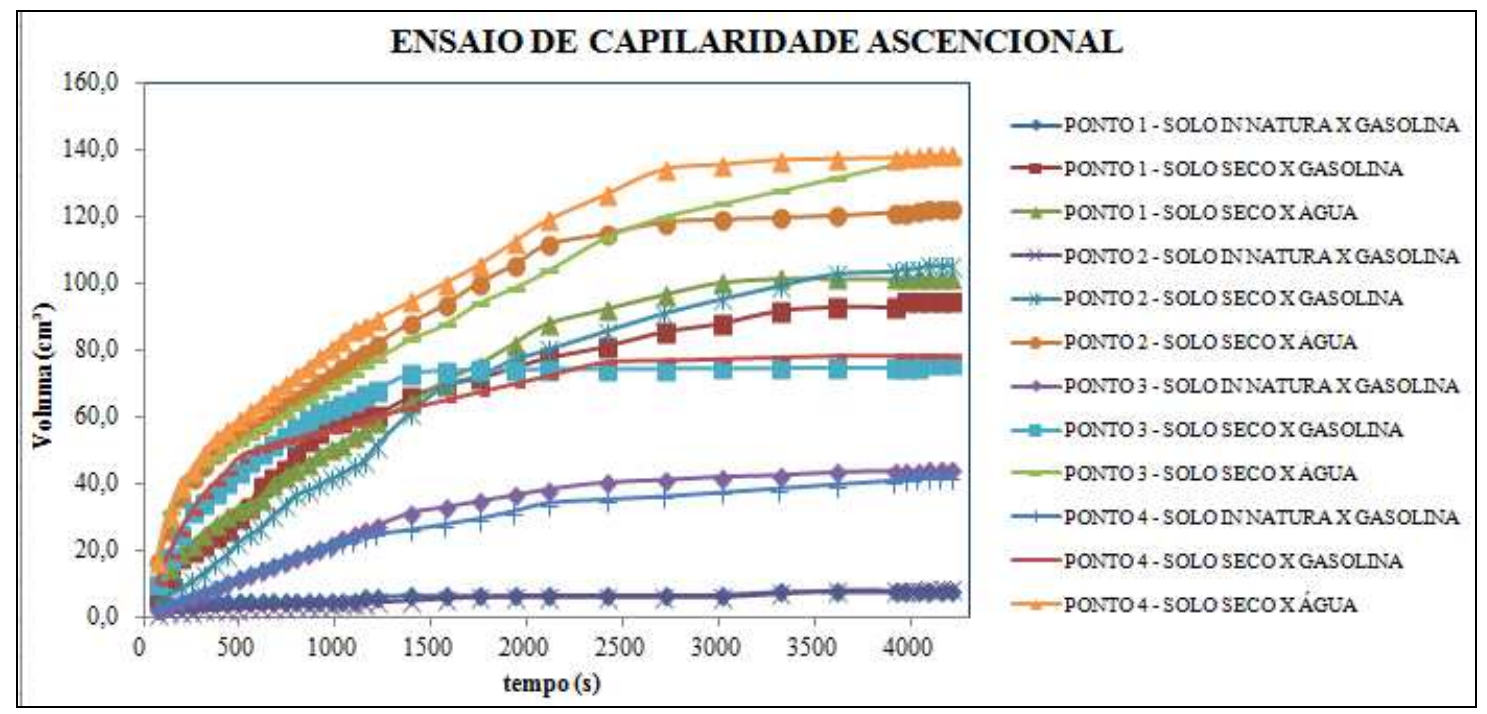

Figura 4 - Ensaio de Absorção por Capilaridade Ascensional.

\section{CONCLUSÕES:}

Após todos os ensaios realizados, é possível concluir que o tipo de solo não influencia o comportamento de absorção por capilaridade, porém altera a capacidade de retenção máxima de líquido.

As amostras de solo analisadas úmidas apresentaram as menores capacidades de retenção de gasolina, pois como já era esperado, o teor de água presente no solo dificulta o movimento ascendente do combustível.

O tipo de solo presente no ponto 1 foi o que apresentou menor índice de absorção e retenção, enquanto o tipo de solo do ponto 2 apresentou a maior capacidade de retenção máxima de líquidos. Já os pontos 3 e 4 apresentaram comportamento intermediário e bastante semelhantes, nestes pontos, mesmo nas amostras úmidas, os solos conseguiram absorver mais 
gasolina, quando comparado aos outros dois tipos de solo, todavia, a quantidade absorvida ainda foi menor, em relação as amostras analisadas secas.

\section{REFERENCIAS}

AGÊNCIA NACIONAL DE PETRÓLEO (ANP). Anuário Estatístico Brasileiro do Petróleo, Gás Natural e Biocombustíveis 2014. Disponível em: <www.anp.gov.br> Acesso em: 27/Jan/2014.

INSTITUTO DAS ÁGUAS DO PARANÁ (ÁGUAS PARANÁ) - Disponível em: $<$ http://www.aguasparana.pr.gov.br/modules/conteudo/conteudo.php?conteudo=57>. Acesso em: 05/Fev/2014.

CORSEUIL, H. X.; MARINS, M.D.M.. Contaminação de águas subterrâneas por derramamentos de gasolina: o problema é grave? Revista Engenharia Sanitária e Ambiental, [s. 1.], v.2, n.2, Diversas Páginas, 1997.

DUARTE, K.S. (2003) Avaliação do Risco Relacionado à Contaminação dos Solos por Hidrocarbonetos no Distrito Federal. Tese de Doutorado em Geotecnica pela Universidade de Brasília. Diversas Páginas.

MILCZEWSKI, P.F. Avaliação Qualitativa dos Riscos Ambientais Gerados por Postos de Combustíveis Localizados na Microbacia Hidrográfica do Rio Bacacheri. 2010. Trabalho de Conclusão de Curso de Nível Superior de Tecnologia em Química Ambiental, Universidade Tecnológica Federal do Paraná, Curitiba, 2010.

MINISTÉRIO DE MEIO AMBIENTE (MMA). Disponível em: <http://www.mma.gov.br/ agua/recursos-hidricos/item/8617-aquífero-guarani> Acesso em: 19/Fev/2014.

RIBEIRO, A.C. (1999). Contribuição ao Conhecimento do Mecanismo da Interação da Gasolina com Solos Residuais Tropicais. Dissertação de Mestrado, UFRJ, Rio de Janeiro, Diversas Páginas.

RIBEIRO, N.C. (2005) Avaliação da Impermeabilização e Ocorrência de Inundações na Bacia do Rio Bacacheri. Dissertação de Mestrado. Curso de Pós-Graduação em Geologia. Universidade Federal do Paraná. Diversas Páginas. 